\title{
Performance Examination and Design Optimization of Thermoelectric Sensor Configuration for Energy Harvesting From Air Conditioner Waste Heat
}

\author{
Ramli Yusof, Herman Wahid, M. Hafis Izran Ishak, Dirman Hanafi, Rozaimi Ghazali
}

\begin{abstract}
Due to energy crisis as well as environmental pollution issues, it is necessity for the establishment of alternatives energy harvester system in reducing the dependency of the primary resources such as oil and coal. The purpose of this research is to investigate working principle of the thermoelectric (TE) which able to harvest waste heat energy through a portable air conditioner and convert it to electrical energy. To optimise the $T E$ performance, a number of TE configurations via experimental analysis are carried out which are significantly affecting the output power and the conversion efficiency of the TE system. From this research, it is concluded that proper design of the TE system is required to improve its energy conversion efficiency.
\end{abstract}

Keywords : Thermoelectric, energy harvesting, waste heat, conversion efficiency, air conditioner.

\section{INTRODUCTION}

T hese days, the demand of electricity is rising rapidly with the growing industries and household electrical appliances. To fulfill these daily requirements, different energy sources like coal, water, wind and solar energy are employed at a very high cost. Some of the the power generation method simply produce huge number of waste heat into the environment. Since heat can be converted even in a small mill watt range, it may has high potential to be recycled for domestic low power lighting usage and in running low power consumption electronic products [1][2]. Thermoelectric device which works with the principle of Seebeck effect converts temperature gradient between the two junctions into voltage and vice versa can be utilize to harness electricity from heat. The output voltage is directly proportional to the temperature difference between the two sides of module. Among which, waste heat recovery by using

Revised Manuscript Received on October 25, 2019.

* Correspondence Author

Ramli Yusof, Universiti Teknologi Malaysia, Johor, Malaysia. Email: kumarun 87@yahoo.com

Herman Wahid*, Universiti Teknologi Malaysia, Johor, Malaysia.. Email: herman@utm.my

M. Hafis Izran Ishak, Universiti Teknologi Malaysia, Johor, Malaysia. Email: hafis.utm.my

Dirman Hanafi, Universiti Tun Hussien Onn Malaysia, Johor, Malaysia. Email:dirman@uthm.edu.my

Rozaimi Ghazali, Universiti Teknikal Malaysia Melaka, Melaka, Malaysia. Email: rozaimi.ghazali@utem.edu.my thermoelectric has become of the most promising technologies to improve the fuel economy and emission reduction of vehicles because of its attributes such as light weight, small size, silence, scalability and no mechanical vibration and chemical erosion [3].

Peltier module is a thermoelectric module that have the ability to convert thermal energy into electrical energy which are made of two semiconductors, one being p-type and another being n-type. The working operation is based on Seebeck effect (conversion of heat into electricity) which occurs inside the Peltier modules [4]. As the heat spreads and starts flowing so does the free charge carriers from the hot side to the cold side. The end voltages are proportional to the temperature difference and the system keeps on generating voltage as long as the temperature differences remain with respect to time and temperature difference. Peltier cells are based on the principle of thermoelectric phenomena [5]. These phenomena are based on the formation of a difference of voltage levels at the junctions of two different metal materials. The first important discovery relating to thermoelectricity occurred in 1821 when a German scientist, Thomas Johann Seebeck, found that an electric current would flow continuously in a closed circuit made up of two dissimilar metals provided that the junctions of the metals were maintained at two different temperatures [6][7]. Fig. 1 illustrates the basic functional blocks of a thermoelectric generator.

From literature, Yildiz in [8] has studied the performance of thermoelectric system through an air conditioner condenser by fabricating a holder and clamper. Both holder and clamper are not only to fix the thermoelectric module but it is made from copper to absorb more heat and transfer to the thermoelectric surface to get higher gradient temperature. An experimental layout of a thermoelectric system setup is shown in Fig. 2. According to the temperature measurements, there is not enough temperature difference between hot and cold plates of the thermoelectric unit that the output voltage is $435 \mathrm{mV}$ due to improper installation which the cold and hot sides are not in parallel configuration. 


\section{Performance Examination and Design Optimization of Thermoelectric Sensor Configuration for Energy Harvesting From Air Conditioner Waste Heat \\ multimeter as depicted in Fig. 4(b).}

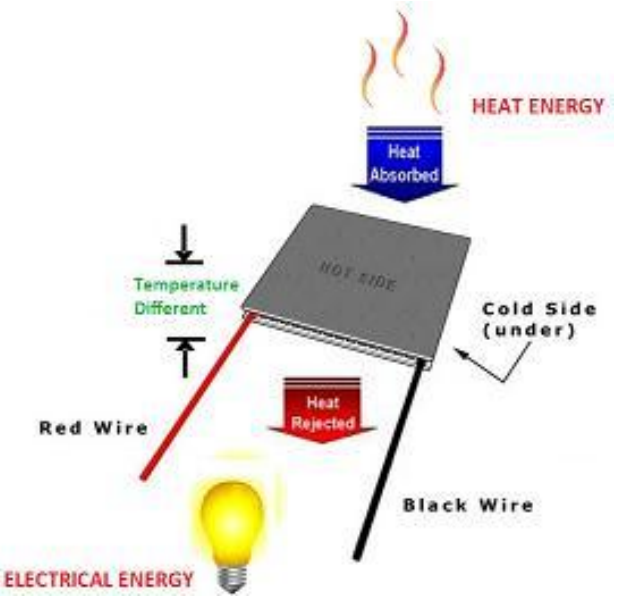

Fig. 1. Basic thermoelectric functional blocks
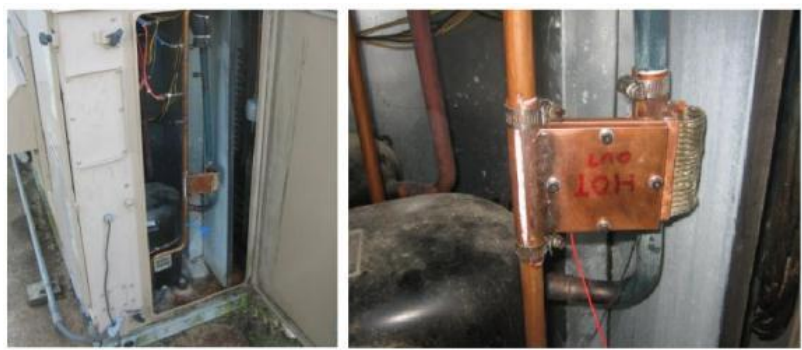

Fig. 2. An experimental layout of a TE system in [8]

In this paper, the performance investigation of the thermoelectric and the best configuration of the thermoelectric are performed on an air conditioner through a number of experiments. The thermoelectric cooler (TEC) module is selected and tested with difference temperature profile and configuration to verify its capability and performance. This paper is prepared and covered as follows: Section 2 describes the methodology of the studies; Section 3 discusses the several experimental results and Section 4 will conclude the experimental analysis.

\section{EXPERIMENTAL SETUP OF THE MEASUREMENT WORK}

The first part of the analysis is to determine the output voltage, current and power within TEC depending on the temperature difference between the hot and cold sides. A comparative study of three selected types of module with same dimension (i.e. $40 \mathrm{~mm} \times 40 \mathrm{~mm}$ ) which are TEC1-12703, TEC1-12706 and TEC1-12706 shown in Fig. 3 (a)-(c) will be conducted. The entire TEC modules were purchased from a local distributor in Malaysia.

The measurement process is started by measuring the output voltage of the TEC module in which different hot side temperature ranging from $40^{\circ} \mathrm{C}$ to $70^{\circ} \mathrm{C}$ are applied (to imitate the heat from the air conditioner compressor). The test is performed by using a hot plate from Fisher Scientific (Model no. 11110250SH) as shown in Fig. 4(a) to provide various range of temperatures as the source for hot side of the TEC module. Temperature sensor with analog output (LM35) and TEC module are connected to the Arduino board to collect the output voltage and the temperature readings via the serial monitor in degree Celsius and Volt, respectively. The output current of TEC is measured by using a digital

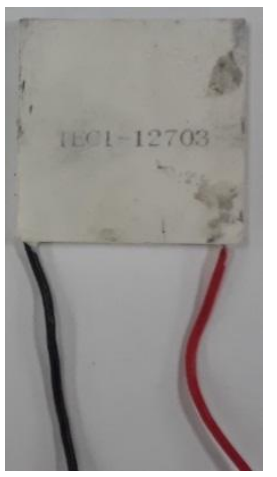

(a)

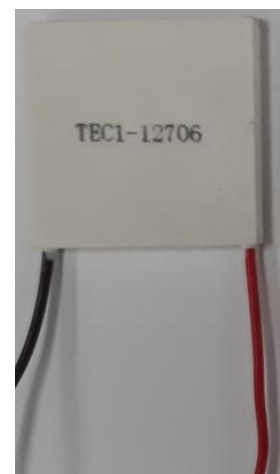

(b)

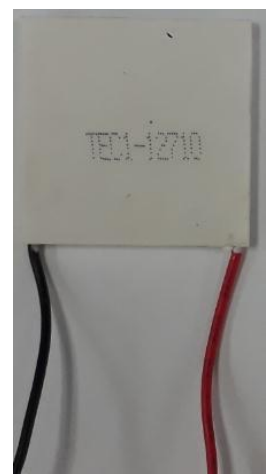

(c)
Fig. 3. TEC modules under investigation: (a) TEC1-12703, (b) TEC1-12706, (c) TEC1-12710

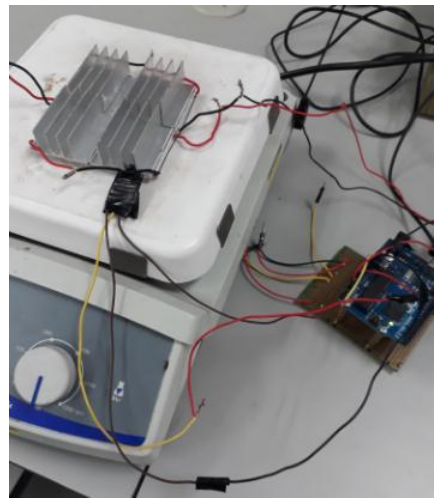

(a)

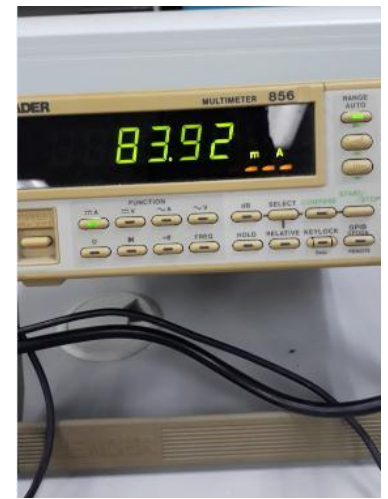

(b)
Fig. 4. (a) Fisher Scientific hot plate, (b) a digital multimeter

\section{MEASUREMENT RESULTS}

\section{A. TEC Module Performance}

The first experiment involves the measurement condition when the hot side is heated on the hot plate and the cold side is exposed to the ambient temperature. A sensor for temperature measurement is placed on the top of TEC module of cold side. The delay time taken to perform this measurement is every 60 seconds for difference range of temperature at hot side which the initial temperature applied to hot side is $40{ }^{\circ} \mathrm{C}$, followed by $50{ }^{\circ} \mathrm{C}, 60{ }^{\circ} \mathrm{C}$ and $70{ }^{\circ} \mathrm{C}$, for each TEC module . The measurements values were recorded and are tabulated in a table. Then each of the data plotted into graphs as shown in Fig. 5 (a)-(d) to identify the characteristic of the temperature that generate the optimum output voltage, current and power.

From the plotted graphs in Fig. 5, it is determined that the average maximum output voltage for each TEC module was obtained when cold side temperature was reached approximately at same hot side temperature applied. This approach is used to identify the type of TEC module which gives the best performance in term of its maximum output voltage for the same level of applied temperature, as tabulated in Table 1. 


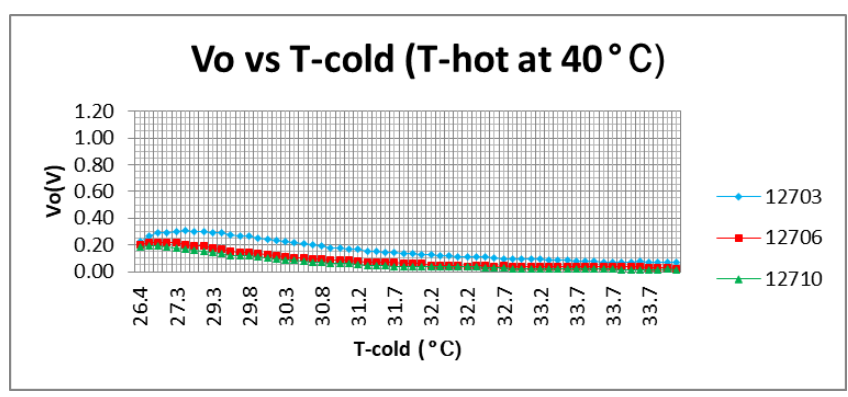

(a)

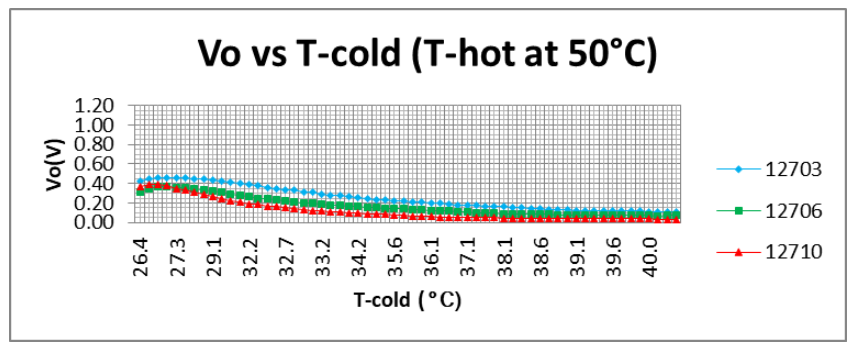

(b)

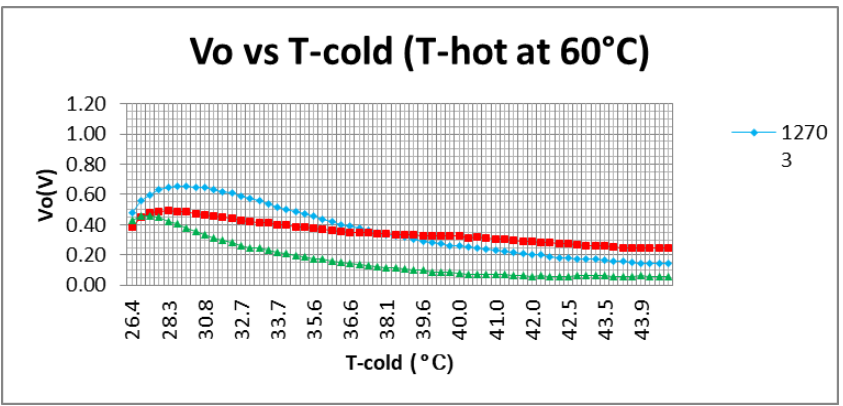

(c)

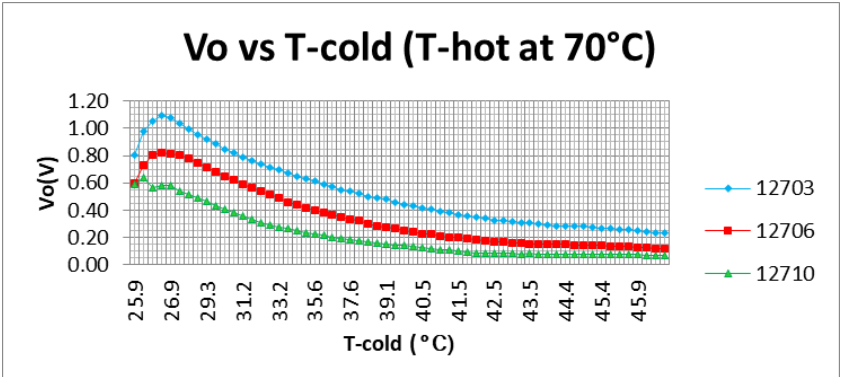

(d)

Fig. 5. TEC's performance for different cold side temperature, when hot temperature is: (a) at $40^{\circ} \mathrm{C}$, (b) at $50^{\circ} \mathrm{C}$, (c) at $60^{\circ} \mathrm{C}$, (d) at $70^{\circ} \mathrm{C}$

Table- I: The optimum temperature for cold side

\begin{tabular}{|c|c|c|c|c|c|}
\hline \multicolumn{2}{|c|}{ T-hot $\left({ }^{\circ} \mathbf{C}\right)$} & $\begin{array}{c}\text { At 40 } \\
{ }^{\circ} \mathbf{C}\end{array}$ & $\begin{array}{c}\text { At 50 } \\
{ }^{\circ} \mathbf{C}\end{array}$ & $\begin{array}{c}\text { At 60 } \\
{ }^{\circ} \mathbf{C}\end{array}$ & $\begin{array}{c}{ }^{\text {At 70 }} \\
{ }^{\circ} \mathbf{C}\end{array}$ \\
\hline \multirow{3}{*}{ T-cold $\left({ }^{\circ}\right.$ C) } & 12703 & 26.9 & 26.9 & 26.4 & 25.9 \\
\cline { 2 - 6 } & 12706 & 26.9 & 26.9 & 26.4 & 25.9 \\
\cline { 2 - 6 } & 12710 & 26.9 & 26.9 & 26.4 & 25.9 \\
\hline
\end{tabular}

In another analysis, the temperature different, produced output voltage, maximum output current and the maximum output power for dfferent TEC type are summarized in Table 2 (a) - (c). Therein the table, the maximum voltage of $1.09 \mathrm{~V}$ is produced by TEC1-12703 at maximum temperature deviation of $44.1^{\circ} \mathrm{C}$. However, the optimal current and output power is given by TEC1-12706 which produces $131.01 \mathrm{~mA}$ and $0.108 \mathrm{~W}$ respectively, even though the generated voltage is slightly lower as compared to TEC1-12703.

Table- II : TEC module performance for: (a) TEC1-12703, (b) TEC1-12706, (c) TEC1-12710

\begin{tabular}{|c|c|c|c|c|c|}
\hline $\begin{array}{l}\text { T-hot } \\
\left({ }^{\circ} \mathrm{C}\right)\end{array}$ & $\begin{array}{c}\text { T-cold } \\
\left({ }^{\circ} \mathrm{C}\right)\end{array}$ & $\Delta \mathbf{T}$ & $\begin{array}{l}\text { Vout } \\
\text { (V) }\end{array}$ & $\begin{array}{l}\text { Max Iout } \\
\quad(\mathbf{m A})\end{array}$ & $\begin{array}{c}\text { Max } \\
\text { Pout } \\
\text { (W) }\end{array}$ \\
\hline 40 & 26.9 & 13.1 & 0.303 & 26.60 & 0.008 \\
\hline 50 & 26.9 & 23.1 & 0.450 & 43.30 & 0.019 \\
\hline 60 & 26.4 & 33.6 & 0.650 & 44.62 & 0.029 \\
\hline 70 & 25.9 & 44.1 & 1.090 & 53.42 & 0.058 \\
\hline \multicolumn{6}{|c|}{ (a) } \\
\hline $\begin{array}{l}\text { T-hot } \\
\left({ }^{\circ} \mathrm{C}\right)\end{array}$ & $\begin{array}{c}\text { T-cold } \\
\left({ }^{\circ} \mathbf{C}\right)\end{array}$ & $\Delta \mathbf{T}$ & Vout (V) & $\begin{array}{c}\text { Max Iout } \\
\text { (mA) }\end{array}$ & $\begin{array}{l}\text { Max } \\
\text { Pout } \\
\text { (W) }\end{array}$ \\
\hline 40 & 26.9 & 13.1 & 0.303 & 26.60 & 0.008 \\
\hline 50 & 26.9 & 23.1 & 0.450 & 43.30 & 0.019 \\
\hline 60 & 26.4 & 33.6 & 0.650 & 44.62 & 0.029 \\
\hline 70 & 25.9 & 44.1 & 1.090 & 53.42 & 0.058 \\
\hline
\end{tabular}

\begin{tabular}{|c|c|l|l|l|l|}
\hline \multicolumn{9}{|c|}{ (b) } \\
\hline $\begin{array}{c}\text { T-hot } \\
\left({ }^{\circ} \mathbf{C}\right)\end{array}$ & $\begin{array}{c}\text { T-cold } \\
\left({ }^{\circ} \mathbf{C}\right)\end{array}$ & $\Delta \mathbf{T}$ & Vout $(\mathbf{V})$ & $\begin{array}{c}\text { Max Iout } \\
(\mathbf{m A})\end{array}$ & $\begin{array}{c}\text { Max } \\
\text { Pout } \\
(\mathbf{W})\end{array}$ \\
\hline 40 & 26.9 & 13.1 & 0.196 & 27.64 & 0.005 \\
\hline 50 & 26.9 & 23.1 & 0.391 & 42.94 & 0.017 \\
\hline 60 & 26.4 & 33.6 & 0.459 & 72.63 & 0.033 \\
\hline 70 & 25.9 & 44.1 & 0.640 & 88.26 & 0.056 \\
\hline
\end{tabular}

The correlation of output voltage, current and power versus time are shown in Fig. 6 (a)-(c). From the plotted graphs, TEC 12703 has maximum output voltage of $1.09 \mathrm{~V}$ at $\Delta \mathrm{T}=44.1$ ${ }^{\circ} \mathrm{C}$, TEC 12706 has maximum output current of $131.01 \mathrm{~mA}$ at $\Delta \mathrm{T}=44.1^{\circ} \mathrm{C}$ and TEC 12706 has maximum output power of $0.108 \mathrm{~W}$ at $\Delta \mathrm{T}=44.1{ }^{\circ} \mathrm{C}$. The obtained low value of output power is identified by experimental measurements whereas the heat at cold side is not being dissipated which it reflect to temperature difference between both sides.

Further experiment is then executed with heat sink. Using the same approach, the experimental measurements of TEC module are conducted. In general, better results are achieved in which heat sink has significantly improve the temperature difference between hot side and cold side, hence increasing especially the output voltage. The results for these experiments are tabulated in Table 3 (a) - (c) TEC module performance with heat sink for : (a) TEC1-12703, (b) TEC1-12706, (c) TEC1-12710. The TEC module performance with heat sink is further illustrated in the correlation form as shown in Fig. 7 (a)-(c). From the plotted graph, TEC 12703 with active heat sink has maximum output voltage of $1.14 \mathrm{~V}$ at $\Delta \mathrm{T}=44.6{ }^{\circ} \mathrm{C}$, TEC 12706 has maximum output current of $160.75 \mathrm{~mA}$ at $\Delta \mathrm{T}=44.6^{\circ} \mathrm{C}$ and TEC 12706 has maximum output power of $0.158 \mathrm{~W}$ at $\Delta \mathrm{T}=44.1 \circ \mathrm{C}$. From the experimental result, it can be observed that the output power had increased about $40 \%$ when heat sink is applied to the cold side of the TEC module. 


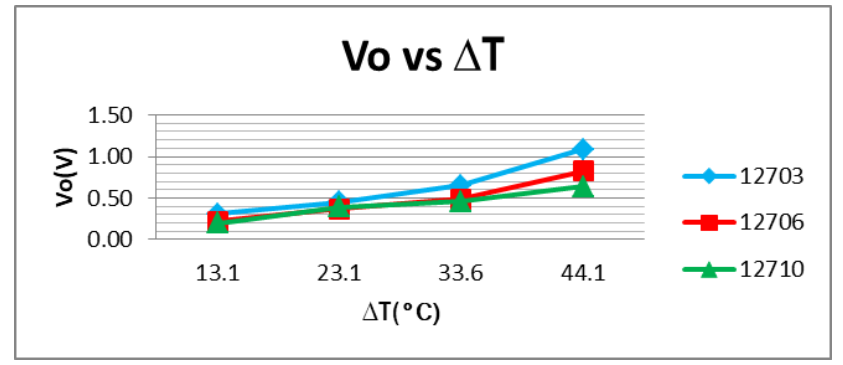

(a)

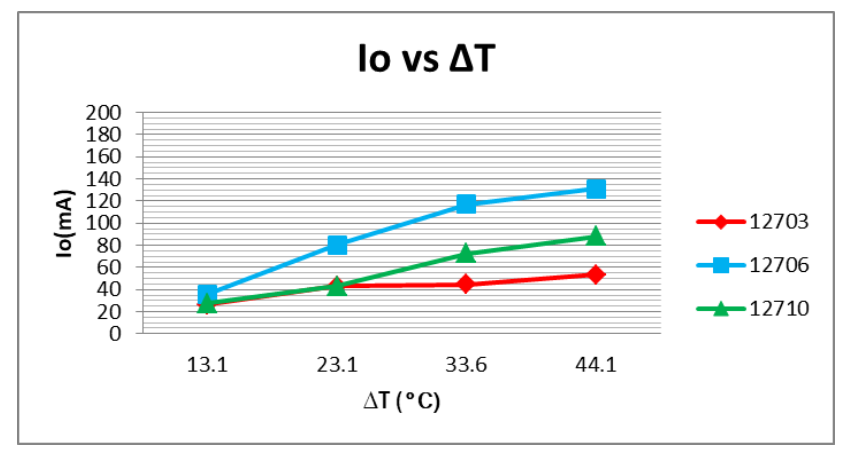

(b)

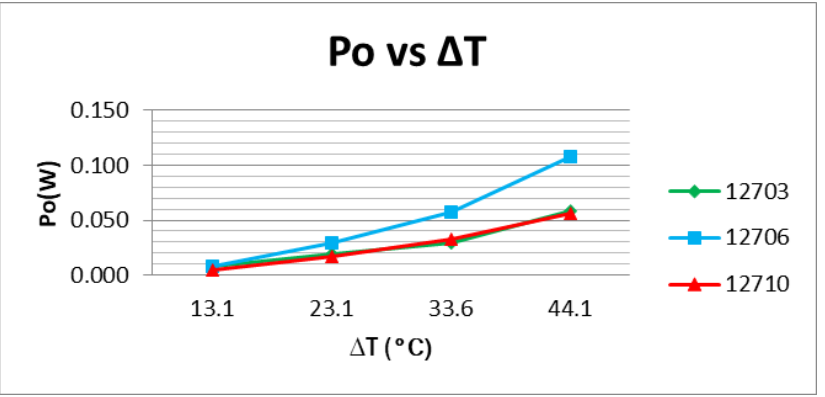

(c)

Fig. 6. TEC's performance for (a) output voltage, (b) output current, (c) output power

Table- III: TEC module performance with heat sink for:

(a) TEC1-12703, (b) TEC1-12706, (c) TEC1-12710

\begin{tabular}{|c|c|c|c|c|c|}
\hline $\begin{array}{c}\mathrm{T} \text {-hot } \\
\left({ }^{\circ} \mathrm{C}\right)\end{array}$ & $\begin{array}{c}\mathrm{T} \text {-cold } \\
\left({ }^{\circ} \mathrm{C}\right)\end{array}$ & $\Delta \mathrm{T}$ & $\begin{array}{c}\text { Vout } \\
(\mathrm{V})\end{array}$ & $\begin{array}{c}\text { Max lout } \\
(\mathrm{mA})\end{array}$ & $\begin{array}{c}\text { Max Pout } \\
(\mathrm{W})\end{array}$ \\
\hline 40 & 26.4 & 13.6 & 0.391 & 44.99 & 0.018 \\
\hline 50 & 25.9 & 24.1 & 0.582 & 55.47 & 0.032 \\
\hline 60 & 25.9 & 34.1 & 0.767 & 76.12 & 0.058 \\
\hline 70 & 25.4 & 44.6 & 1.114 & 84.27 & 0.094 \\
\hline
\end{tabular}

(a)

\begin{tabular}{|c|c|c|c|c|c|}
\hline $\begin{array}{c}\mathrm{T} \text {-hot } \\
\left({ }^{\circ} \mathrm{C}\right)\end{array}$ & $\begin{array}{c}\mathrm{T} \text {-cold } \\
\left({ }^{\circ} \mathrm{C}\right)\end{array}$ & $\Delta \mathrm{T}$ & $\begin{array}{c}\text { Vout } \\
(\mathrm{V})\end{array}$ & $\begin{array}{c}\text { Max lout } \\
(\mathrm{mA})\end{array}$ & $\begin{array}{c}\text { Max Pout } \\
(\mathrm{W})\end{array}$ \\
\hline 40 & 26.4 & 13. & 0.2 & 63.92 & 0.018 \\
\hline 50 & 25.9 & 24. & 0.4 & 86.49 & 0.036 \\
\hline 60 & 25.9 & 34. & 0.6 & 129.17 & 0.082 \\
\hline 70 & 25.4 & 44. & 0.9 & 160.75 & 0.158 \\
\hline
\end{tabular}

(b)

\begin{tabular}{|c|c|c|c|c|c|}
\hline $\begin{array}{c}\text { T-hot } \\
\left({ }^{\circ} \mathrm{C}\right)\end{array}$ & $\begin{array}{c}\mathrm{T} \text {-cold } \\
\left({ }^{\circ} \mathrm{C}\right)\end{array}$ & $\Delta \mathrm{T}$ & $\begin{array}{c}\text { Vout } \\
(\mathrm{V})\end{array}$ & $\begin{array}{c}\text { Max lout } \\
(\mathrm{mA})\end{array}$ & $\begin{array}{c}\text { Max Pout } \\
(\mathrm{W})\end{array}$ \\
\hline 40 & 26.4 & 13. & 0.4 & 35.43 & 0.015 \\
\hline 50 & 25.9 & 24. & 0.4 & 79.47 & 0.036 \\
\hline 60 & 25.9 & 34. & 0.4 & 103.61 & 0.052 \\
\hline 70 & 25.4 & 44. & 0.8 & 126.13 & 0.112 \\
\hline
\end{tabular}

(c)

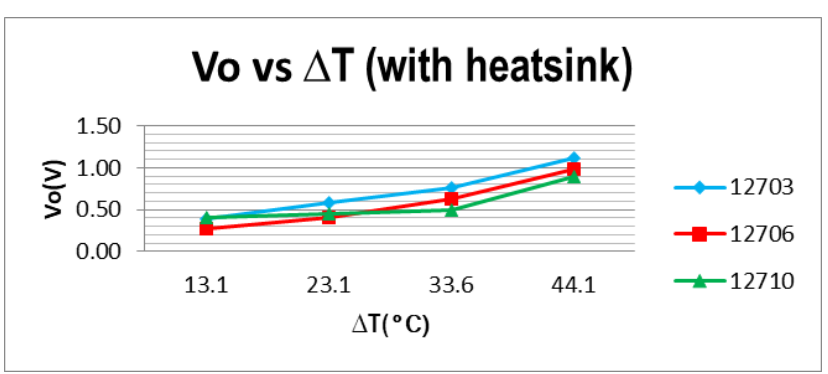

(a)

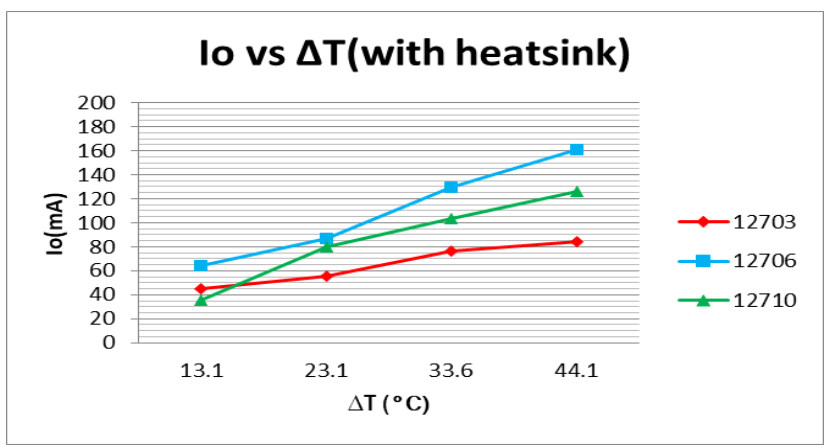

(b)

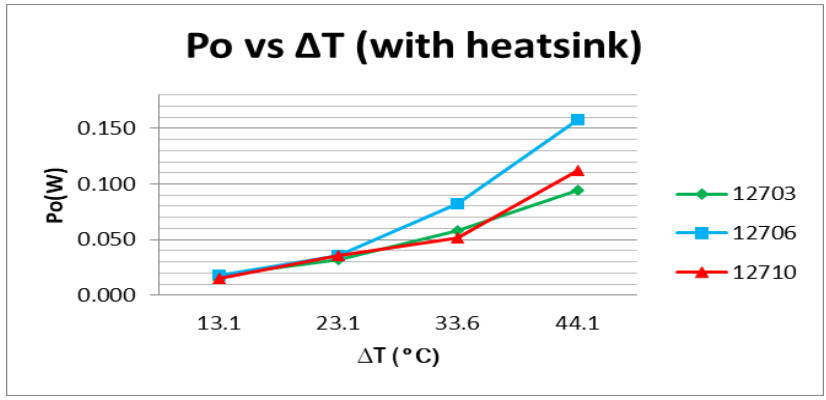

(c)

Fig. 7. TEC's performance with heat sink for (a) output voltage, (b) output current, (c) output power

\section{B. TEC Performance for Different Configuration}

In order to access the impact of TEC module from waste heat of air conditioner, verification is done to get the optimum point of heat released which may contribute to high temperature difference. It was identified that the compressor area had released the highest temperature. To measure the temperature from waste heat, a temperature sensor is attached on body of the compressor and air conditioner is run for 1 hour with variation of air conditioner's operating temperature setting which ranging from $16{ }^{\circ} \mathrm{C}$ to $30^{\circ} \mathrm{C}$. From collected data, the temperature profiles are plotted as shown in Fig. 8. It has been observed that the highest temperature obtained when the air conditioner operated at setting temperature of $16^{\circ} \mathrm{C}$.

Next, the experiments of three different configurations which are described below are carried out. As referred to the previous analysis, TEC- 12706 is selected here for the following experiments, as it has given the best performance for the maximum output power.

1. Configuration A: The TEC is attached directly to the compressor.

2. Configuration B: The TEC is equipped with heat sink and mechanical structure. By implementing the mechanical structure as shown in Fig, it is expected that released heat from

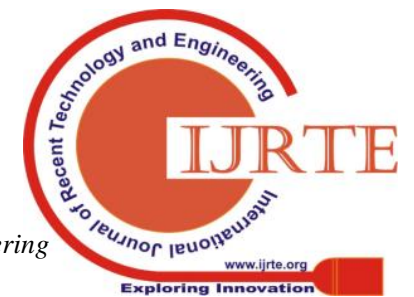




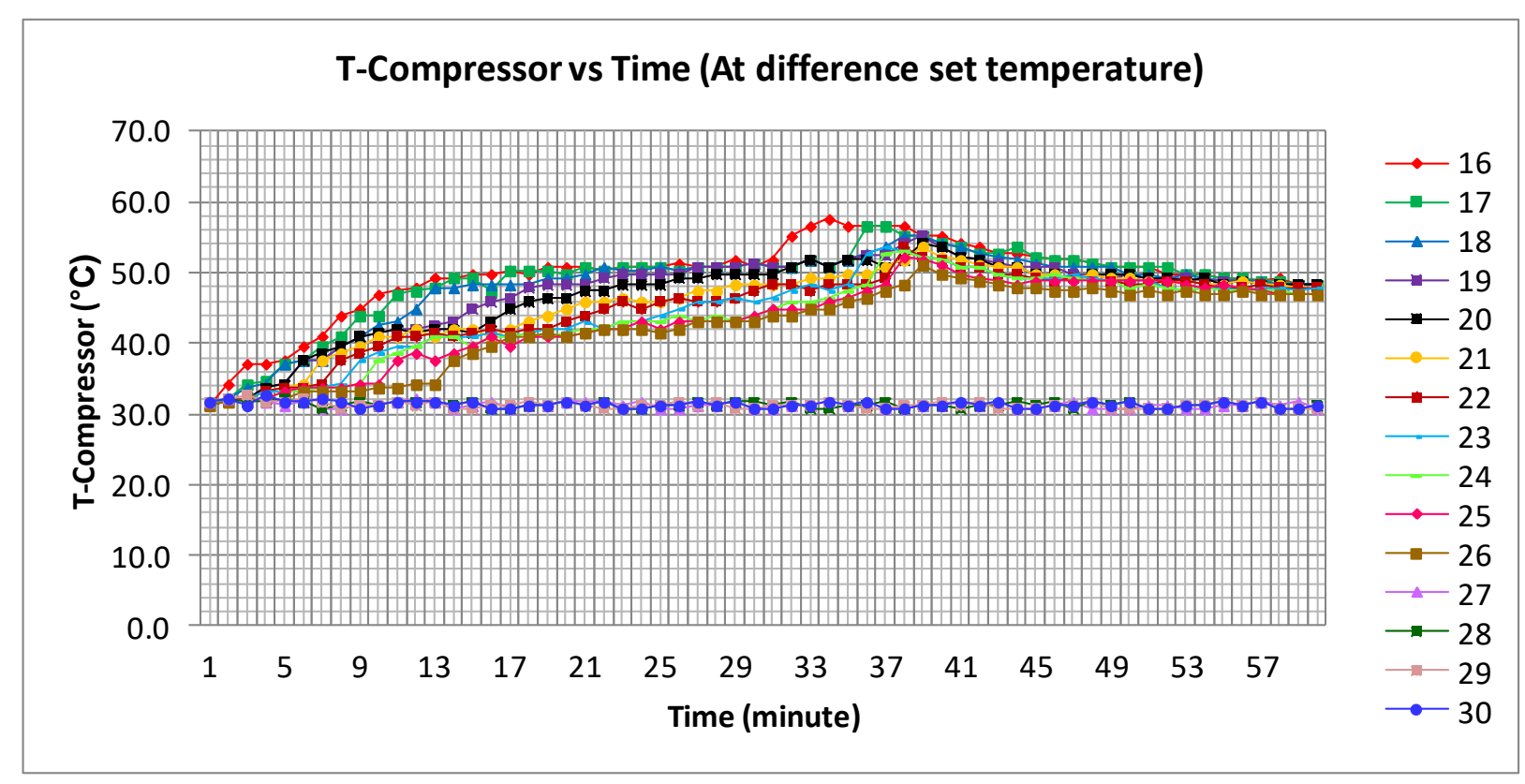

Fig. 8. Temperature rising during the operation of air conditioner's compressor

compressor is insulated, hence heat rate around the TEC module is improved.

3. Configuration $\mathbf{C}$ : The TEC is equipped with heat sink, mechanical structure and graphene sheet as shown in Fig. Thin graphene sheet had been placed at both sides of hot sides which are not contacted to the curve surface of the compressor. This method is expected could absorb more heat from the surface of compressor and increase the heat transfer to the hot area of the TEC module.

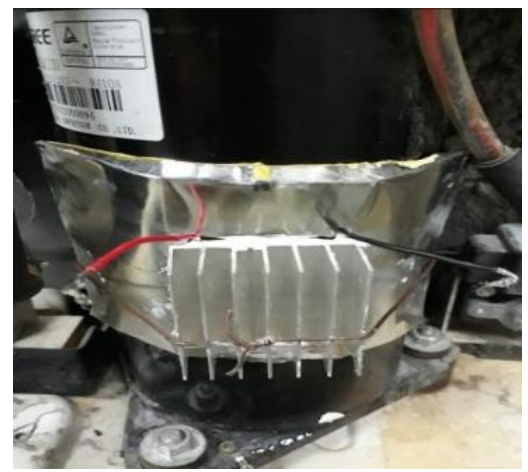

Fig. 9. Configuration C : TEC with mechanical heat absorption structure and graphene sheet

The different readings of the temperature and output voltage for different configuration are recorded in and summarised in the plotted graph as shown in Fig.

As referred to the summary result as shown in Table 4, by comparing the results of configuration $\mathrm{B}$ and $\mathrm{C}$ with the one with configuration $\mathrm{A}$, it can be found that significant improvement occur in term of the amount of temperature difference, which will apparently generate more electrical energy. The results of configuration B indicates that the use of heat sink can increase the temperature difference between two sides of TEC module and improvement result is also found by adding the mechanical structure to the TEC module. The result of configuration $\mathrm{C}$ indicates that the result can be further improved significantly by implementing graphene sheet to absorb more heat transfer from the curve area.

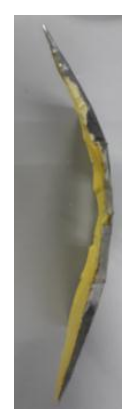

(a)

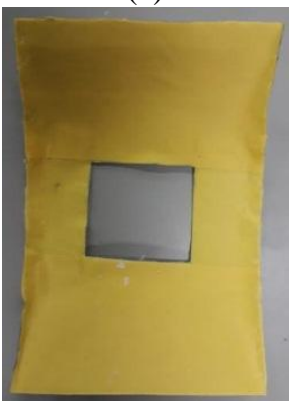

(c)

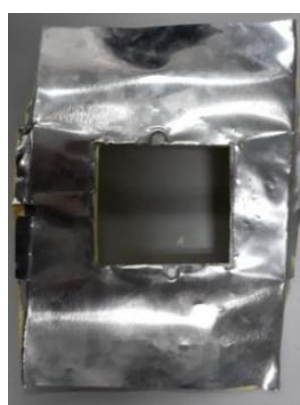

(b)

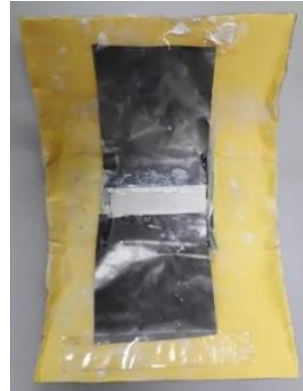

(d)
Fig. 10. Mechanical structure for (a) side view, (b) top view, (c) internal view, (d) internal view with graphene sheet

\section{CONCLUSION AND FUTURE WORKS}

TEC module produces voltage when there is the temperature difference between the both surfaces which it works on the principle of Seebeck effect. This work considered some type of TEC module with difference configuration by utilize some arrangement that provides heating and cooling to the opposite sides of TEC module. TEC module had been applied through portable air conditioner at compressor area to harvest electrical energy from waste heat. A single TEC

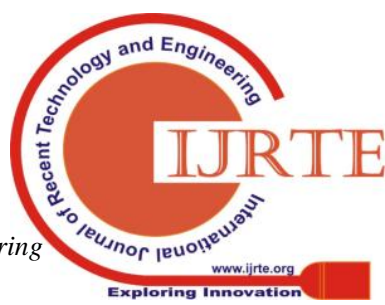




\section{Performance Examination and Design Optimization of Thermoelectric Sensor Configuration for Energy Harvesting From Air Conditioner Waste Heat}

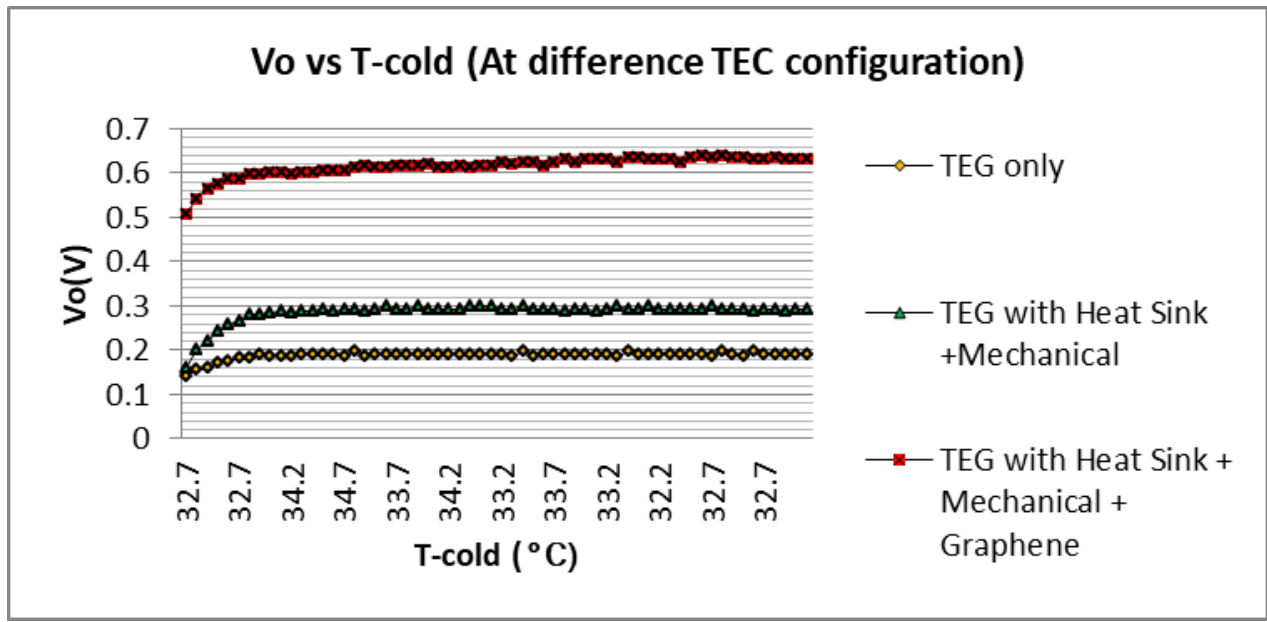

Fig. 11. Output voltage vs Temperature for different TEC configuration

Table- IV: Comparison of output performance for different configuration of TEC module

\begin{tabular}{|c|c|c|c|c|c|c|}
\hline Configuration & TEG & $\begin{array}{c}\text { Heat Sink + } \\
\text { Mechanical } \\
\text { Structure }\end{array}$ & $\begin{array}{c}\text { Graphene } \\
\text { Sheet }\end{array}$ & $\begin{array}{c}\text { Max Output } \\
\text { Voltage (V) }\end{array}$ & $\begin{array}{c}\text { Relative Increment } \\
\text { (Compare with A) }\end{array}$ & $\begin{array}{c}\text { Relative Increment } \\
\text { (Compare with B) }\end{array}$ \\
\hline A & Yes & No & No & 0.191 & - & - \\
\hline B & Yes & Yes & No & 0.298 & $56 \%$ & - \\
\hline C & Yes & Yes & Yes & 0.640 & $235 \%$ & $114 \%$ \\
\hline
\end{tabular}

managed to obtain up to $1.09 \mathrm{~V}$ with the temperature difference of about $44^{\circ} \mathrm{C}$.

The results were also showing positive effect of TEC module configuration with additional of heat sink, mechanical structure and graphene sheet. Besides, there are some new improvements of configuration could be done such as using heat sink from other materials for better conductivity, proper insulation material for the inner side of mechanical structure and implement thicker graphene sheet for inner side of mechanical structure .

In particular, to improve the performance of the overall TEC system, the implementation of the power management such as DC to DC converter should be highly considered. It is necessary to adopt this converter in the TEC system to provide more stable power output as well as to improve its efficiency.

\section{ACKNOWLEDGMENT}

The authors express gratitude to the Malaysian Ministry of Education (MOE) and UniversitiTeknologi Malaysia for research grant with vote number $17 \mathrm{H} 40$ for supporting this work.

\section{REFERENCES}

1. W. He, G. Zhang, X. Zhang, J. Ji , G. Li and X. Zhao, "Recent development and application of thermoelectric generatorand cooler," Applied Energy, vol. 143, pp. 1-25, Jan. 2015.

2. F. Meng, L. Chen and F. Sun, "A numerical model and comparative investigation of a thermoelectric generator with multi-irreversibilities," Energy, vol. 36. pp. 3513-3522, Apr. 2011.

3. J. Yang and F.R Stabler, "Automotive applications of thermoelectric materials. "Jurnal of Electronic Materials," vol. 38, no.7, pp. 1245-1251, 2009.

4. L.C. Chuan, H. Wahid , H.A. Rahim and Ruzairi, R.A. Rahim, "A review of thermoelectric energy harvester and its power management approach in electronic applications. " Jurnal Teknologi, vol. 73, no.3, pp. 153-159, Dec. 2015.

5. Seebeck T.J. Ueber die magnetische Polarisation der Metalle und Erze durch Temperatur-Differenz. Ann. Phys. 1826;82:133-160. doi: 10.1002/andp.18260820202.

6. D.K. Aswal, R. Basu and A. Singh, "Key issues in development of thermoelectric power generators: Highfigure-of-merit materials and their highly conducting interfaces withmetallic interconnects," Energy Conversion and Management, vol. 114. pp. 50-67, Feb. 2016.

7. M.H Elsheikh, D.A Shnawah ,M.F.MSabri, S.BM Said , M.H Hassan , M.B.A Bashir, M. Mohamad, "A review on thermoelectric renewable energy: Principle parametersthat affect their performance," Renewable and Sustainable Energy Reviews, vol. 30, pp. 337-355, Nov. 2013.

8. Y. Yildiz, K.L. Coogler and Sam, "Low Power Energy Harvesting with a Thermoelectric Generator through an air conditioning condenser." American Society for Engineering Education (ASEE)," pp. 24.8877.1-24.877.12, 2014.

\section{AUTHORS PROFILE}

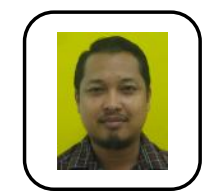

Ramli Yusof has obtained Bachelor's Degree in Industrial Electronics Engineering in 2008 from $\mathrm{He}$ is currently pursuing his Master Philosophy studies in Universiti Teknologi Malaysia.

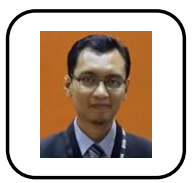

Herman Wahid received the B.Eng. in Electrica Engineering (Instrumentation and Control) in 2000, and M.Eng in Electrical Engineering (Mechatronics and Automatic Control) in 2007 from Faculty of Electrical Engineering, Universiti Teknologi Malaysia (UTM), Malaysia. He then obtained his Ph.D from University of Technology, Sydney (UTS), Australia in 2013. He has five years experience in industry (2000-2005) and is currently a Senior Lecturer in UTM. His research interests include artificial intelligences, controller design and optimization, environmental quality instrumentation and energy harvesting system. 


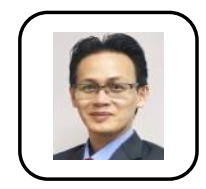

M. Hafis Izran Ishak received his B.Eng. in electrical engineering (Mechatronics) in 2002, and M.Eng in electrical engineering (Mechatronics and Automatic Control) in 2005 from Faculty of Electrical Engineering, Universiti Teknologi Malaysia (UTM), Malaysia. He then received his Ph.D from Loughborough University, United Kingdom in 2011, which his work focuses on the quantification of human skill in applications for Human Adaptive Mechatronics. His research interest: Human Adaptive Mechatronics, Human Machine System, Artificial Intelligence, Fuzzy Logic, Neural Network, Unmanned Aerial Vehicles, Mobile Apps, Internet of Things, Technology in Agriculture, and Autonomous Vehicle.

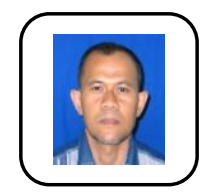

Dirman Hanafi is currently working at Universiti Tun Hussein Onn Malaysia, Johor. His research interest includes Intelligent Control System System, Identification, Artificial Intelligent, Robotics. He is serving as an honorary author for Global Journal of Technology and Optimization. He has authored of several H1 research articles/books related to Control Engineering and Technology. His research interest includes Intelligent Control System, Identification, Artificial Intelligent and Robotics.

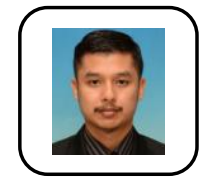

Rozaimi Ghazali received the B.Eng. (Electrical Instrumentation and Control) in 2008, and Ph.D in Electrical Engineering in 2013 from Universiti Teknologi Malaysia (UTM), Malaysia. He is currently a Senior Lecturer in UTM. His research interests include Adaptive Robust Control, Sliding Mode Control, System Identification, Hydraulic and Pneumatic Systems, and Motion Control. 